\title{
An Hermeneutic Analysis of Transpersonal Education: Policies, Principles and Practices
}

\author{
Scott Buckler \\ University of Worcester, UK
}

\begin{abstract}
Maslow was instrumental to the development of humanistic and transpersonal psychology advocating that humanistic psychology should be subsumed by transpersonal psychology [1]. However the transpersonal has remained a lucid term with oversimplified definitions relating to spirituality [2-5], although three encompassing themes have been identified: beyond-ego psychology, integrative psychology and transformative psychology [6]. Although transpersonal psychology has been applied to a number of fields, (e.g. counselling, coaching, psychotherapy), there has been a paucity of research in relation to mainstream education. This paper initially introduces and discusses transpersonal psychology and how it differs to humanistic and positive psychology, before hermeneutically analysing previous research on transpersonal education, to propose a transpersonal education for the twenty-first century.
\end{abstract}

\section{Introduction}

There appears to be an unprecedented period of change: every day the media streams a variety of images which demonstrates the exponential developments occurring on a national and global scale. Such events may affect us on a personal or collective scale and we can feel disempowered due to nature and rate of such change. Envisioning how the world will change in the next decade or two is akin to guessing next week's lottery numbers. Consequently how can we as educators, prepare today's children for tomorrow's society?

As a response to such a question, in 2006 the Department for Education and Skills (a Government body within England that operated from 2001-7) considered five key drivers of change that would affect the country leading towards the year 2020. These drivers related to the pace of technological developments, greater social diversification, a heightened awareness of environmental issues, demographic tensions (where there would be more over-65s than under-16s), and economic tensions (where more luxuries would become necessities, alongside the need for young people to be better qualified to secure employment, and a diversity or working patterns) [7].

Despite attempts to predict how the education of today should respond to the uncertainty of tomorrow, this paper discusses the need for a radical review of the curriculum: one which encompasses developing themes within psychology to empower children on an individual level so that they may engage fully within future society. Such psychological themes stem from the humanist perspective, namely positive psychology (an area which has gathered increasing momentum in the past decade) and the more inclusive field of transpersonal psychology.

Transpersonal psychology can be dated to Maslow's writings circa. 1966; indeed Maslow perceived humanistic psychology as a transitional field of psychology subsumed within transpersonal psychology [7]. However, since its inception, transpersonal psychology has remained relatively unknown outside small intellectual circles [8] despite Fontana asserting that the transpersonal is arguably the oldest branch of psychological enquiry [9].

Yet what is transpersonal psychology? Simply defined, the 'transpersonal' has been interpreted as 'beyond the person': 'trans' translated from Latin as 'beyond' or 'through', and 'personal' from the Latin for 'mask' [10-12]. Unfortunately ascertaining deeper interpretations of the nature and content of transpersonal psychology is problematic due to the variety of perspectives and themes within the field. While Daniels lists a range of areas related to transpersonal psychology, reluctantly summarising these as 'spirituality' [13], Rowan adopts a different perspective, specifying boundaries to the concept, specifically that the 'transpersonal' is not to be confused with the extra-personal, the New Age, religion or spirituality [14]. An additional interpretation is that transpersonal psychology synthesises Western psychology with Eastern contemplative traditions [15-17].

Through an analysis of thirty-five years of research into transpersonal psychology, Hartelius, Caplan and Rardin identified three encompassing themes: beyond-ego psychology, integrative/holistic psychology, and the psychology of transformation [18]. The first theme, beyond-ego psychology, examines the ego, its pathologies and the concept of 
exploration beyond the ego. The second theme attempts to identify how a single psychology for the whole person can be constructed, an approach which combines different psychological perspectives. The third theme is concerned with understanding and cultivating growth as individuals and as communities. Hartelius et al respectively refer to the themes as the content (the actual transpersonal states), the context (through which human experience is studied, for example, the beliefs, attitudes and intentions), and the catalyst (where such growth relates to personal and social transformation). These themes are demonstrated in Figure 1.

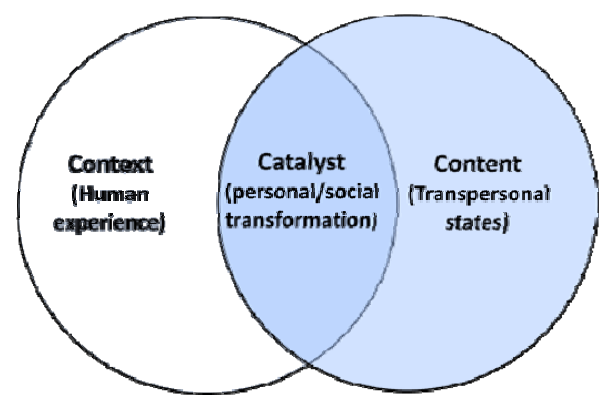

\section{Figure 1. The three themes of transpersonal psychology (adapted from Hartelius et al).}

Succinctly defined, Hartelius et al concluded that transpersonal psychology examines human transcendence, wholeness, and transformation. From this definition, transpersonal psychology aims to transform humanity, both individually and collectively, for the positive. However this emphasis on the positive can be confused with an alternate, developing area of psychology, positive psychology.

\section{Positive psychology vs. humanistic psychology}

Maslow originally used the term 'positive psychology' (which he also called, 'orthopsychology') as an approach focusing on fully functioning and healthy human beings [19]. More recently, however the term has become synonymous with the partnership of Martin Seligman and Mihalyi Csikszentmihalyi. According to Robbins, positive psychology focuses on positive subjective experiences (e.g. 'flow', joy, optimism, well-being, contentment, happiness, satisfaction), the personality traits of thriving individuals (e.g. character strengths and virtues), also the enhancement of social institutions to sustain and develop positive subjective experience [20], or what Seligman refers to as the 'three pillars' of positive psychology [21]. Although positive psychology and humanistic psychology may appear synonymous [22], Seligman and Csikszentmihalyi criticise humanistic psychology as lacking an empirical research tradition which they assert is required for any psychological approach, given the positivist nature of the psychology [23]. In defence of humanistic psychology, Taylor identifies a range of themes that have been empirically researched [24], while others have provided counterarguments against positive psychology, which relate specifically to the inherent value system adopted by positive psychology [25-28]. Leontiev provides an additional criticism, that positive psychology is more of an ideology, lacking a unified theoretical explanatory model [29]. Furthermore, Martin asserts that there is little difference between positive psychology and educational psychology; that both aim to create optimal conditions for human development and learning, through emphasising positive levels of self-esteem, self-concept, selfefficacy, and self-regulation [30].

One core tension that positive psychology needs to address is discussed by Hart and Sasso, whereby positive psychology has become as much a popular culture movement (referred to as 'Happiology' or the science of happiness) as it has as a fledgling academic subject [31].

Despite such criticisms of positive psychology, one area has received significant attention; Csikszentmihalyi's concept of 'flow', a state where one is absorbed, there is a sense of self-control, a loss of self-consciousness where action and awareness merge, associated with a transformation of time [32, 33]. Although Csikszentmihalyi and Csikszentmihalyi report that flow enables a person to grow and to achieve their potential through obtaining this pleasurable state [34], Boniwell warns that such flow activities can be morally good or bad, for example citing the workaholic who ignores spending time with their children, or the compulsive gambler [35]. An additional criticism is raised by Buckler who discusses the similarities between the flow experience and Maslow's concept of selfactualisation, suggesting that there is little to distinguish between each state, and that both have inherent flaws [36].

Given the on-going tension between positive psychology and humanistic psychology, such sibling rivalry is unlikely to resolve within the foreseeable future, despite both sharing the same foundation. Yet Maslow critiqued his own humanistic psychology, superseding this with transpersonal psychology, in turn advocating that research should focus on selftranscendence (specifically in relation to the plateau experience) [37, 38]. Consequently although positive psychology may continue to receive increased attention, the reader should be critically aware of some of the tensions, similarly developing a further awareness of the subtle, yet important differences between positive psychology, humanistic psychology and transpersonal psychology. 


\section{The transpersonal related to education}

Rothberg advocates that the area of education 'is one of the most significant areas of future inquiry and exploration in the transpersonal field' [39]. Cunningham supports this assertion, reporting that, 'dialogue on the topic of education in transpersonal psychology is indeed one of the most crucial needs now facing transpersonal psychology today' [40]. Yet Rothberg warns against the controversies and challenges of such a discussion, whereby he identifies the potential misunderstandings and tensions alongside cultural, intellectual, political, economic and academic contexts [41].

Perhaps this is the fundamental reason why, since its inception, transpersonal psychology related to education has remained significantly dormant. Indeed Maslow's writings seldom discuss education, despite every student teacher's awareness of the hierarchy of needs. Consequently in an attempt to promote discussion of the transpersonal within education, or more succinctly, 'transpersonal education', a series of considerations are synthesised from available literature.

It is important to highlight that the majority of sources appear dated, demonstrating the limited focus on transpersonal education since the inception of transpersonal psychology. This is possibly due to the issues previously raised by Rothberg and Cunningham. Consequently, a hermeneutic approach has been adopted, which compares interpretations from the past with those from the present. Robson defines 'hermeneutics' as both a philosophical orientation and a methodology in an attempt to make sense of the world [42], through recovering and reconstructing the intentions of others through analysis of meaning [43-47]. This hermeneutical approach will adhere to Ralph Tyler's principles of curriculum design: what educational purposes should the curriculum seek to attain (the policy), what educational experiences can be provided to attain these purposes (the practices), how can the educational experiences be effectively organised (the principles), and how can it be determined whether the purposes have been attained (the product) [48]. In adherence to the first three areas, transpersonal education will be discussed through the policy, principles, and practices (Figure 2).

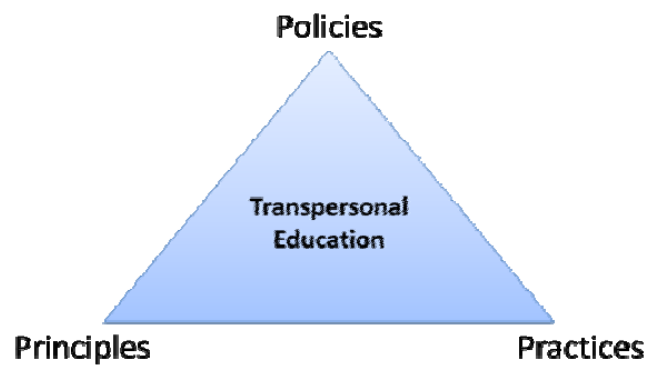

Figure 2. Tyler's principles of curriculum design.

\subsection{Policy}

According to Moore, transpersonal education should attempt to combine the cognitive, affective and psychomotor domains (Figure 3), in that the mind and body should no longer be considered as separate entities (which he describes as jockey and horse) [49]. Such mind/body integration is similarly promoted by Roberts and Clark [50], while Rothberg advocated that transpersonal education should unite the aforementioned domains, while similarly integrating the spiritual domain [51].

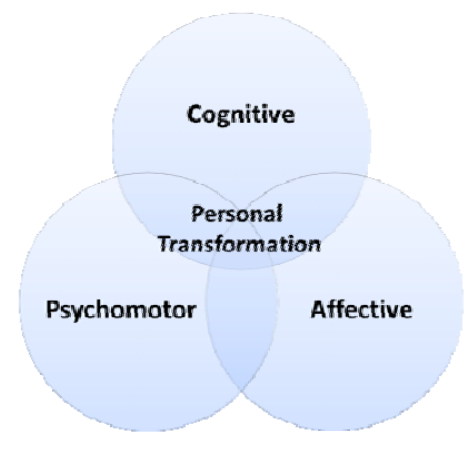

Figure 3. Uniting the human domains through transpersonal education.

Such a unified attempt to develop and integrate the aforementioned domains would support Maslow's assertion that the purpose of education is for a child to become a healthy, self-actualised (or self-transcended) adult [52, 53]. To promote such personal transformation, Maslow discussed the need for both parents and teachers to continue to personally develop to prevent their own patterns of behaviour being conveyed to the child [54]. Indeed, this relates to Firman and Gila's concept of 'the primal wound', whereby experiences commencing in early childhood, and continuing through life, results in a violation of individuality affecting the intrinsic, authentic self, where 'we are torn away from human being and thrust toward human nonbeing, and our sense of self is profoundly wounded' [55]. Such 
wounding may be overt or covert, yet such wounding Firman and Gila assert, can be a social, political or cultural phenomenon. Consequently, Firman and Gila assert that teachers and parents should resolve their primal wounds, moving towards their own personal transformation, which in turn will limit subsequent 'wounding' to children. One way to achieve this is to promote effective communication across the interpersonal, intrapersonal and transpersonal domains [56].

As an example, if a parent feels that their toddler is 'testing the boundaries' by dropping food on the floor, rearranging the furniture, removing cushions, throwing objects, along with a multitude of other such behaviours, the parent may get cross with the child, perceiving the child to be 'naughty' and therefore enforce a range of discipline measures (for example, the 'time out' step as discussed in the introduction to this chapter). Yet the behaviours exhibited by the toddler are all examples of 'play schemas', or patterns of play, where the child is exploring and making sense of their world [57, 58]. For example, dropping food or throwing objects relates to the trajectory schema, rearranging furniture can be explained through the transporting, positioning or enclosure schema, etc. Understanding schemas consequently explains the developing child's behaviour, consequently, if a parent gets cross with a child for such behaviour aiming to diminish rather than encourage the pattern of play, the child is being denied a chance to develop and make sense of their world.

A further example of how a parent's behaviour may be conveyed to a child is through driving. Perhaps a minor misdemeanor from another road user manifests in the parent providing a sign of agitation (e.g. some form of gesture): the child travelling in the car may in turn believe that it is fine to lose their temper with others in an aggressive way. Yet if the parent does not feel threatened by other road users and is in control of their cognition (how they perceive other road users), their emotions (whether or not they feel personally threatened by other road users) and their subsequent psychomotor displays (whether they indicate the error of another road users' ways through some form of gesticulation), then the developing child can see a calm and collected adult as a model for their own behaviour.

\subsection{Principles (General)}

A series of principles for transpersonal education can be deduced through the literature: arguably many of these themes resonate within the education profession as models of effective practice. Such an example advocated by Maslow [59] and Moore [60] is that learning should be joyful. This could be achieved through promoting intrinsic learning [61] through developing learner autonomy [62], and that learning should be a process of self-discovery [63]. Such education should be value-free and promoted by the teacher in the role of a facilitator [64-66].

\subsection{Principles (Specific)}

Alongside the general principles for transpersonal education, specific principles can be identified which outline operational considerations. Central to transpersonal education is the discovery of the inner depths of the individual and the essential human nature [67], alongside facilitating an appreciation of awe and beauty, especially in relation to the interrelation of all things $[68,69]$ or what Maslow terms 'a unitive experience' [70]. This can be achieved through an openness to experience [71, 72], and through a pragmatic approach of linking theory to practice [73].

The general and specific principles of transpersonal education are summarised in Figure 4.

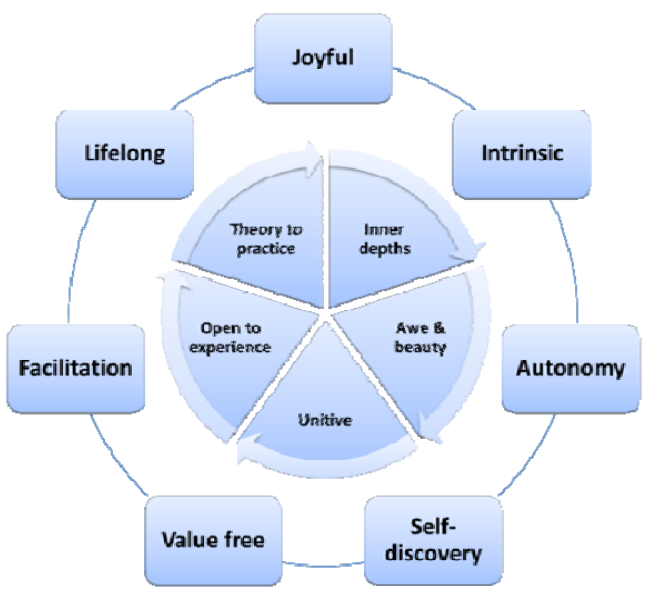

Figure 4. The general principles of transpersonal education (outer ring) and specific principles of transpersonal education (inner ring).

\subsection{Practices}

To promote the transpersonal, a series of practices have been advocated, although it must be noted that those presented here are representative and not an exhaustive list. Practices such as relaxation and meditation are promoted by Roberts and Clark [74], additionally 'mindfulness' has recently received significant attention, where a person concentrates on a physical task (e.g. breathing, eating, drinking, exercise, etc.) in an attempt to synthesise mind and body [75, 76]. Indeed the area of Mindfulness-based Cognitive Therapy (MBCT) has recently received a 
lot of academic attention in the treatment of depression, despite the practice being grounded in global meditative traditions spanning centuries.

Indeed, Walsh provides the most comprehensive list of transpersonal practices based on the perennial philosophy, or the 'common core of both wisdom and practices at the heart of each authentic tradition' [77]. (Such 'authentic tradition' relates to religious, or spiritual/philosophical traditions). The practices Walsh highlights are: redirecting motivation (through reducing craving and identifying higher reaches of desire), transforming emotions (through cultivating emotional wisdom, e.g. reducing fear and anger while nurturing feelings of love and gratitude), living ethically, developing concentration to calm the restless mind, refining awareness to see the sacred and connectedness of all things, cultivating wisdom, practicing service and generosity (Figure 5).

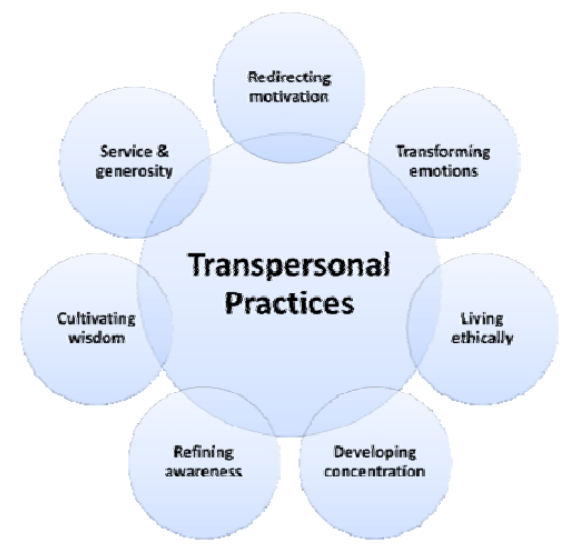

Figure 5. Walsh's seven transpersonal practices.

A further area originally advocated by Maslow for future research, especially in relation to selftranscendence, is the plateau experience [78]. The plateau experience, Maslow asserts, is less emotive than the peak experiences associated with selfactualisation: instead they are a noetic awareness characterised by mindfulness, serenity and a unitive perception resulting in a reduced anxiety of death $[79,80]$, aspects which Maslow suggests can be developed within children [81]. Indeed, there are parallels between the practices Walsh advocates and those that Maslow reports are characterised by the plateau experience, for example, mindfulness relates to Walsh's practice of developing concentration, while the unitive perception in turn relates to Walsh's practice of refining awareness.

Buckler [82] has attempted to ascertain whether the plateau experience is just a theoretical musing from Maslow, or whether it can actually be assessed. He has subsequently developed the PLEX-3, a psychometric utilising previously validated measures for mindfulness, serenity and death anxiety (the three characteristics of the plateau experience). The fifteen-item PLEX-3 was developed through a variety of stages using a sample totalling 863 participants, and has demonstrated good psychometric properties (the Cronbach alpha value of $r=.816$ to .873 , with a two week test-retest reliability of $r=.733)$. The sample for the PLEX-3 consisted of $n=349$ (female $42 \%$, male 58\%) with an age range of 18 to 65 years (mean 30.90, SD 12.62).

Although the PLEX-3 has indicated that the plateau experience exists, further validation studies are required with appropriate samples engaged in what may be deemed transpersonal practices.

In returning to Tyler's principles of curriculum design, the plateau experience is offered to address his fourth principle: whether the educational purposes of the curriculum have been attained, or the product of such policies, principles and practices. Consequently, the plateau experience may demonstrate the impact of such a transpersonal education to education.

\section{Conclusions and Future Work}

The policy behind transpersonal education is that it should bring a synthesis of different domains (e.g. cognitive, affective, psychomotor) to promote personal transformation by developed facilitators (e.g. teachers, primary caregivers) through effective interpersonal, intrapersonal and transpersonal domains.

As a series of principles, transpersonal education should be value-free and joyful, promoting learner autonomy through a process of self-discovery. Additionally, transpersonal education should encourage exploration of the essential human nature and the way in which the person relates on a larger scale to other people and nature, whereby a sense of awe and beauty can be promoted. Such experience should capitalise on linking theory to practice through experience.

Transpersonal education can be promoted through a range of practices advocated by Walsh, for example developing concentration through mindfulness, or through further analysis of the plateau experience which Maslow reports is characteristic of self-transcendence, and implicitly, the transpersonal.

The themes identified are not new: arguably many of the individual elements have previously been advocated and utilised within education, yet this paper attempts to synthesise such elements, while promoting a twenty-first century vision of transpersonal education. How could such a transpersonal education be utilised within the education context? Moore provides three suggestions: (i) apply the transpersonal to existing subjects; (ii) select activities and studies which lead to an awareness of the transpersonal; or (iii) incorporate many new areas into the curriculum [83]. Such considerations should be embraced by 
educationalists either individually or collectively to prepare children for an uncertain future or unprecedented change.

In conclusion, in 1975 Kantor suggested a thorough investigation of man's inner world is required, to rival and surpass space exploration in interest and importance [84]. Indeed through a hermeneutical perspective, at a time of monumental social, economic and political change, one could question the exponential budgets invested in particle accelerators and the theoretical musings of the edges of the universe, at the expense of the wonder central to us... the wonder of being human, or human being.

\section{References}

[1, 7, 19, 53] Maslow, A.H. (1987). Motivation and Personality: Third Edition. Delhi: Pearson Education, Inc. (p.293)

[2, 8, 9, 12, 13] Daniels. M. (2005). Shadow, Self, Spirit: Essays in Transpersonal Psychology. Exeter: Imprint Academic.

[3, 14] Rowan, J. (2005). The Transpersonal: Spirituality in Psychotherapy and Counselling Second Edition. London: Routledge.

[4] Sandage , S.J. \& Jankowski, P.J. (2010). Quest and spiritual development moderated by spiritual transformation. Journal of Psychology and Theology, $38: 1,15-31$

[5, 9] Fontana, D. (2003). Psychology, Religion, and Spirituality. Leicester/Oxford: BPS Blackwell.

[6, 18] Hartelius, G., Caplan, M. and Rardin, M.A. (2007). Transpersonal psychology: Defining the past, divining the future. The Humanistic Psychologist, 35(2), 135-160.

[7] Department for Education and Skills (2006). 2020 Vision: Report of the Teaching and Learning in 2020 Review Group. Nottingham: DfES Publications.

[10, 17] Fontana, D. \& Slack, I. (2005). The Need for Transpersonal Psychology. Transpersonal Psychology Review: Special Issue, Winter 2005, 711.

[11, 15] Ferrer, J.N. (2002). Revisioning Transpersonal Theory: A Participatory Vision of Human Spirituality. Albany: State University of New York Press.

[16] Miller, C. (1991). Self-actualization and the consciousness revolution. Behaviour and Personality, 6:5, 109-126.
[20] Robbins, B.D. (2008). What is the good life? Positive psychology and the renaissance of humanistic psychology. The Humanistic Psychologist, 36, 96-112.

[21] Seligman, M.E.P. (2002). Authentic Happiness. New York: Free Press.

[22, 28] McDonald, M. \& O’Callaghan, J. (2008). Positive psychology: A Foucauldian critique. The Humanistic Psychologist, 36, 127-142.

[23] Seligman, M.E.P and Csikszentmihalyi, M. (2000). Positive psychology: An introduction. American Psychologist, 55, 5-14.

[24] Taylor, E. (2001). Positive Psychology and Humanistic Psychology: A Reply to Seligman. Journal of Humanistic Psychology, 41:1, 13-29.

[25] Held, B. S. (2002). The tyranny of the positive attitude in America: Observation and speculation. Journal of Clinical Psychology, 58, 965-991.

[26] Miller, A. (2008). A critique of positive psychology - or 'the new science of happiness'. Journal of Philosophy of Education, 42:3-4, 591608.

[27] Sundararajan, L. (2005). Happiness donut: A Confucian critique of positive psychology. Journal of Theoretical and Philosophical Psychology, 25:1, 35-60.

[29] Leontiev, D. (2006). 'Positive personality development: Approaching personal autonomy’. In Csikszentmihalyi, M. and Csikszentmihalyi, I.S. (Eds.) (2006). A Life Worth Living: Contributions to Positive Psychology. New York: Oxford University Press, Inc.

[30] Martin, J. (2006). Self research in educational psychology: A cautionary tale of positive psychology in action. The Journal of Psychology, 140:4, 307316, (p.308).

[31] Hart, K.E. and Sasso, T. (2011). Mapping the contours of contemporary positive psychology. Canadian Psychology, 52:2, 82-92.

[32] Csikszentmihalyi, M. (2000). Beyond Boredom and Anxiety: Experiencing Flow in Work and Play. San Francisco: Jossey Bass Inc, Publishers.

[33] Csikszentmihalyi, M. (2002). Flow: The Classic Work on How to Achieve Happiness, London: Rider.

[34] Csikszentmihalyi, M. \& Csikszentmihalyi, I. (Eds.) (1988). Optimal Experience: Psychological 
Studies of Flow in Consciousness. Cambridge: Cambridge University Press.

[35] Boniwell, I. (2006). Positive Psychology in a Nutshell: A Balanced Introduction to the Science of Optimal Functioning. London: PWBC.

[36, 38, 82] Buckler, S. (2011). The Plateau Experience: Maslow's Unfinished Theory. Saarbrücken, Germany: Lambert Academic Publishing.

[37, 78, 81] Krippner, S. (Ed.) (1972). The Plateau Experience: A.H. Maslow and Others. Journal of Transpersonal Psychology, 2:2, 107-120.

[39, 41, 51, 64, 69, 72] Rothberg, D. (2005). Transpersonal Issues at the Millennium. Transpersonal Psychology Review: Special Issue, Winter 2005, 81-102, (p. 89).

[40] Cunningham, P.F. (2006). Transpersonal Education: Problems, Prospects and Challenges. The International Jounral of Transpersonal Studies. 25, 62-68, (p. 63)

[42] Robson, C. (2002). Real World Research: A Resource for Social Scientists and PractitionerResearchers (Second Edition). Oxford: Blackwell Publishing.

[43] Braud, W. \& Anderson, R. (1998).Transpersonal Research Methods for the Social Sciences: Honouring Human Experience. London: Sage Publications, Ltd.

[44] Cohen, L., Manion, L. \& Morrison, K. (2007). Research Methods in Education: Sixth Edition. London: Routledge.

[45] Fielding, N. (2010). Mixed methods research in the real world. International Journal of Social Research Methodology, 13:2, 127-138.

[46] Haslam, S.A. \& McGarty, C. (2003). Research Methods and Statistics in Psychology. London: Sage Publications Ltd.

[47] Kincheloe, J.L. \& Berry, K.S. (2004). Rigour and Complexity in Educational Research: Conceptualizing the Bricolage. Maidenhead: Open University Press.

[48] Tyler, R.W. (1949). Basic Principles of Curriculum and Instruction. Chicago: University of Chicago Press.
[49, 60, 65, 83] Moore, T.W. (1975). Transpersonal Education: A Preview. Journal of Education, 157:4, 24-39.

[50, 72, 74] Roberts, T. and Clark, F.V. (1976). 'Transpersonal Psychology in Education'. In Hendricks, G. and Fadiman, J. (Eds.) (1976). Transpersonal Education: A Curriculum for Feeling and Being. Englewood Cliffs: Prentice-Hall (3-23).

[52, 54, 59, 64, 72] Maslow, A.H. (1971). The Farther Reaches of Human Nature. London: Penguin Books.

[55] Firman, J. and Gila, A. (1997). The Primal Wound: A Transpersonal View of Trauma, Addiction, and Growth. Albany, NY: State University of New York Press, (p. 93).

[56] Weinhold, B.K. (1975). 'Transpersonal communication in the classroom'. In Hendricks, G. and Fadiman, J. (Eds.) (1976). Transpersonal Education: A Curriculum for Feeling and Being. Englewood Cliffs: Prentice-Hall (123-150).

[57] Nutbrown, C. (2011). Threads of Thinking: Schemas and Young Children's Learning. London: Sage Publications, Ltd.

[58] Wood, E. and Attfield, J. (2005). Play, learning and the Early Childhood Curriculum (Second Edition). London: Sage Publications, Ltd.

[63, 67] Maslow, A.H. (1970). Religions, Values, and Peak-Experiences. New York: Penguin Compass.

[62, 66] Kirchschenbaum, H. (1975). 'What is Humanistic Education?’. In Roberts, T.B. (Ed.) (1975). Four Psychologies Applied to Education: Freudian, Behavioural, Humanistic, Transpersonal. Cambridge, MA: Schenkman Publishing Company (327-329)

[63, 65, 71] Rogers, C.R. (1961). On Becoming A Person: A Therapist's View of Psychotherapy. London: Constable.

[76] Kabat-Zinn, J. (2001). Full Catastrophe Living: How to Cope with Stress, Pain and Illness Using Mindfulness Meditation. London: Piatkus Books.

[75, 77] Walsh, R. (1999). Essential Spirituality: The 7 Central Practices to Awaken Heart and Mind. Exercises from the World's Religions to Cultivate Kindness, Love, Joy, Peace, Vision, Wisdom, and Generosity. New York: John Wiley \& Sons, Inc. (p.6) 
[80] Cleary, T.S. \& Shapiro, S.I. (1995). The Plateau Experience and the Post-Mortem Life: Abraham $\mathrm{H}$. Maslow's Unfinished Theory. The Journal of Transpersonal Psychology, 27:1, 1-23.

[84] Kantor, R. (1975). 'The affective domain and beyond'. In Roberts, T.B. (Ed.) (1975). Four Psychologies Applied to Education: Freudian, Behavioural, Humanistic, Transpersonal. Cambridge, MA: Schenkman Publishing Company (406-416). 